Article

\title{
Mediterranean Diet Adherence is Associated with Lower Prevalence of Functional Gastrointestinal Disorders in Children and Adolescents
}

\author{
Charalampos Agakidis ${ }^{1, *(\mathbb{D}}$, Evangelia Kotzakioulafi ${ }^{2}{ }^{\mathbb{D}}$, Dimitrios Petridis ${ }^{3}$, \\ Konstantina Apostolidou ${ }^{2}$ and Thomai Karagiozoglou-Lampoudi ${ }^{2}$ (D) \\ 1 1st Pediatric Department, Aristotle University of Thessaloniki, Ippokration General Hospital, \\ Konstantinoupoleos 49, 54246 Thessaloniki, Greece \\ 2 Department of Nutrition and Dietetics, Alexander Technological Educational Institute of Thessaloniki, \\ 57400 Thessaloniki, Greece; evelinakotzak@hotmail.com (E.K.); nantia@otenet.gr (K.A.); \\ thomaiskl@gmail.com (T.K.-L.) \\ 3 Department of Food Technology, Alexander Technological Educational Institute of Thessaloniki, \\ 57400 Thessaloniki, Greece; petridis@food.teithe.gr \\ * Correspondence: cagakidis@gmail.com; Tel.: +30-694-768-7799
}

Received: 12 May 2019; Accepted: 4 June 2019; Published: 6 June 2019

\begin{abstract}
Dietary patterns may have a role in the prevention of functional gastrointestinal disorders (FGIDs). The current study aimed at examining the association between FGIDs and adherence to the Mediterranean diet (MD) among elementary school children (ESC), as well as high school students (HSS). In a prospective cohort study, data from 1116 subjects (387 ESC and 448 HSS) aged 6-18 years were collected. FGID identification was based on the Questionnaire on Pediatric Gastrointestinal Symptoms-Rome III (QPGS-RIII). Adherence to the MD was assessed using the KIDMED Index. Full data were available on 835/1116 questionnaires. Based on Rome III criteria, 184/835 participants (22\%) were identified with FGID (122 (66\%) with functional constipation (FC)). The prevalence of FGIDs $(p=0.001)$ was significantly higher in HSS (13-18 years). The KIDMED score in the cohort was $5.7 \pm 2.5$. Subjects with FGIDs demonstrated a lower KIDMED score compared to the non-FGID group, both in the cohort, as well as in the ESC and HSS subgroups (FGID vs. non-FGID: $p=0.001$, $p=0.007$, and $p=0.032$, respectively). Multivariate analysis highlighted the KIDMED score as a significant predictor of FGIDs and FC after controlling for the age subgroups. We conclude that good adherence to the MD is associated to lower prevalence of FGIDs, while adolescents display a significantly higher prevalence of FGIDs compared to children.
\end{abstract}

Keywords: functional constipation; functional gastrointestinal symptoms; KIDMED score; MedDiet; QPGS-III; survey.

\section{Introduction}

Functional gastrointestinal disorders (FGIDs) include a combination of multiple, chronic or recurrent symptoms, which cannot be attributed to any structural disease after thorough biochemical and histological investigation [1]. Recent studies reported a prevalence of $20.7 \%$ in children (four to 12 years) and $26.6 \%$ in adolescents (13 to 18 years) for at least one FGID using the Rome III criteria, suggesting that FGIDs may represent the most common cause of gastrointestinal complaints [2]. The absence of specific biochemical tests and evidence of underlying organic disease may lead to under-diagnosis or/and undertreatment of pediatric FGIDs [1,3,4]. Nevertheless, FGIDs have a significant impact on the quality of life for both patients and their families and increase the utilization of healthcare resources, thereby increasing healthcare costs. 
Although the Rome IV updated criteria suggested a role of psychological factors in the pathogenesis of FGIDs, the gut microbiota dysbiosis, differentiation of gut function through visceral hypersensitivity leading to increased perception of pain and discomfort, disturbed bowel motility, as well as the immune and inflammatory reactions of the gut are also involved [4-7]. The fact that occasionally symptoms appear following food intake and are improved following simple diet modifications emphasizes the need to explore the association between diet and FGIDs [8-11]. Clinical studies in pediatric patients showed that nutritional intervention through intake of a diet consisting of probiotics, fiber, and a low fermentable oligo-, di-, and monosaccharides, and polyols (the FODMAP diet) has a beneficial clinical effect, although available data are inadequate for definitive conclusions [12-18].

There are data suggesting that the Mediterranean diet (MD) might be beneficial in ameliorating functional gastrointestinal symptoms through the increased fiber and antioxidant consumption and the low intake of saturated fats and oligosaccharides $[19,20]$. However, information on the compliance with the MD of children and adolescents suffering FGID is scarce.

The aim of this study was to examine the potential association between FGIDs and adherence to the MD in elemental school children (ESC) and high school students (HSS).

\section{Material and Methods}

\subsection{Study Population and Methods}

This was a prospective cohort study of ESC (6-12 years) and HSS (13-18 years) attending a complex of public schools situated in the Eastern part of Thessaloniki (an urban area inhabited by typical upper-middle income families). During April, May, and June 2017, two questionnaires were given to each student: (1) The Questionnaire for Pediatric Gastrointestinal Symptoms-Rome III (QPGS-III), that is specifically designed to diagnose FGIDs in children and adolescents, translated in the Greek language, and properly validated [21]. The parent-report form was used for subjects aged between 6-12 years and the researchers were available over the phone to provide clarification. The printed version of the self-report form for subjects aged between 13-18 years was completed in the presence of one of the researchers, who were available for queries to ensure complete understanding. (2) A food frequency questionnaire to assess the MD adherence by calculation of the KIDMED score [22].

Data were collected from 1116 children and adolescents (662 ESC and 454 HSS). Based on their responses, participants were classified into two FGID-related groups: Subjects with evidence of at least one FGID (FGID group) and those without evidence of FGID (non-FGID group). The FGID group was further divided into two subgroups: The functional constipation (FC) subgroup and the other-FGID subgroup including all participants presenting FGIDs other than FC. On the basis of KIDMED score, the study population was divided into three MD adherence-related categories: The good, the average, and the poor MD adherence categories, corresponding to KIDMED scores of $\geq 8,4-7$, and $<4$, respectively. In addition, participants were further classified into two age-related subgroups: The subgroup of children attending elementary school (the ESC subgroup, age 6-12 years), and the subgroup of high school students (the HSS subgroup, age 13-18 years).

The study was conducted in accordance with the declaration of Helsinki and Guidelines for Good Clinical Practice and was approved by the Hellenic Ministry of Education. In addition, permission to contact the students was obtained from the school coordinators. The parents received written thorough description of the study procedures and provided written consent. All data were collected anonymously, while information on the participants' gender was not recorded, because in some cases this would be equivalent to disclosing personal information.

\subsection{Statistical Analysis}

Continuous variables were expressed as means and standard deviations and categorical variables as counts and percentages. Differences between groups were assessed using the Mann-Whitney U test and the Fisher's test, as appropriate. A generalized linear model (binary logistic model) was used to 
assess the independent association of the FGID prevalence with the KIDMED score and age-related subgroups. The threshold for significance was set at $p<0.05$, while Bonferroni correction for the number of groups was performed. The statistical analysis was performed using IBM SPSS ${ }^{\circledR}$ software, version 21 (IBM Inc, Chicago, IL, USA).

\section{Results}

\subsection{Functional Gastrointestinal Disorder Prevalence in the Study Population.}

Full data on KIDMED scores were available on 835/1116 questionnaires and only these were considered appropriate for further analysis. This sample consisted of 387 ESC (age $8.75 \pm 1.7$ years) and 448 HSS (age $14.5 \pm 1.8$ years). Based on the Rome III criteria, 184 out of 835 participants were identified with at least one FGID (22.0\%) (FGID group) and 651 (78\%) students without evidence of FGID (non-FGID group) (Table 1). Among the 184 students with FGID, $122(66 \%)$ had functional constipation (FC subgroup) and $62(34 \%)$ had various other FGIDs (other-FGID subgroup), which included cyclic vomiting syndrome $(1.09 \%)$, rumination syndrome $(0.54 \%)$, aerophagia $(6.6 \%)$, functional dyspepsia (2.37\%), irritable bowel syndrome (IBS, $11.34 \%)$, abdominal migraine $(10.33 \%)$, functional abdominal pain $(1.09 \%)$, and functional abdominal pain syndrome $(0.54 \%)$. The prevalence of FC and other FGIDs in the cohort was $14.6 \%$ and $7.4 \%$, respectively $(p<0.001)$. Compared to the ESC, the HSS had a significantly higher prevalence of FGIDs $(p=0.001)$, and other FGIDs $(p<0.001)$, but a comparable prevalence of FC ( $p=0.625$, Table 1$)$.

Table 1. Prevalence ( $n$ (percent)) of functional gastrointestinal disorders (FGIDs) in the cohort and the two age-related subgroups.

\begin{tabular}{lcccc}
\hline \multirow{2}{*}{ FGID Groups \& Subgroups } & Cohort & \multicolumn{3}{c}{ Age-Related Subgroups } \\
\cline { 3 - 5 } & & ESC & HSS & $\boldsymbol{p}^{*}$ \\
\hline$n$ & 835 & 387 & 448 & \\
Non-FGID & $651(78.0)$ & $320(82.7)$ & $331(73.9)$ & 0.001 \\
FGID & $184(22.0)$ & $67(17.3)$ & $117(26.1)$ & 0.625 \\
$\quad$ FC & $122(14.6)$ & $54(14.0)$ & $68(15.1)$ & $<0.001$ \\
$\quad$ Other-FGID & $62(7.4)$ & $13(3.6)$ & $49(10.9)$ & \\
\hline
\end{tabular}

* Fisher's exact test for the difference between the two age-related subgroups. Differences in the cohort: FC vs. non-FGID, $p<0.001$; other-FGID vs. non-FGID, $p<0.001$; FC vs. other FGIDs, $p<0.001$. FGID, functional gastrointestinal disorders; FC, functional constipation; ESC, elementary school children; HSS, high school students.

\subsection{KIDMED Score Relation with Functional Gastrointestinal Disorder Prevalence}

In the cohort, the KIDMED score in participants without FGID was higher compared to the FGID group ( $p=0.001)$ as well as to the FC ( $p=0.030)$ and other-FGID subgroups ( $p=0.008$, Figures 1 and 2$)$. Subgroup comparisons showed that the KIDMED score did not differ significantly between the FC and other-FGID subgroups ( $p=0.030$, with the significance being set at 0.017 after Bonferroni correction for the number of groups, Figures 1 and 2). Significant differences in the KIDMED score were also found within each age-related subgroup, as shown in Figures 1 and 2. Comparisons between the ESC and HSS subgroups showed that the KIDMED score did not differ significantly between the respective FGID subgroups (Figures 1 and 2). 


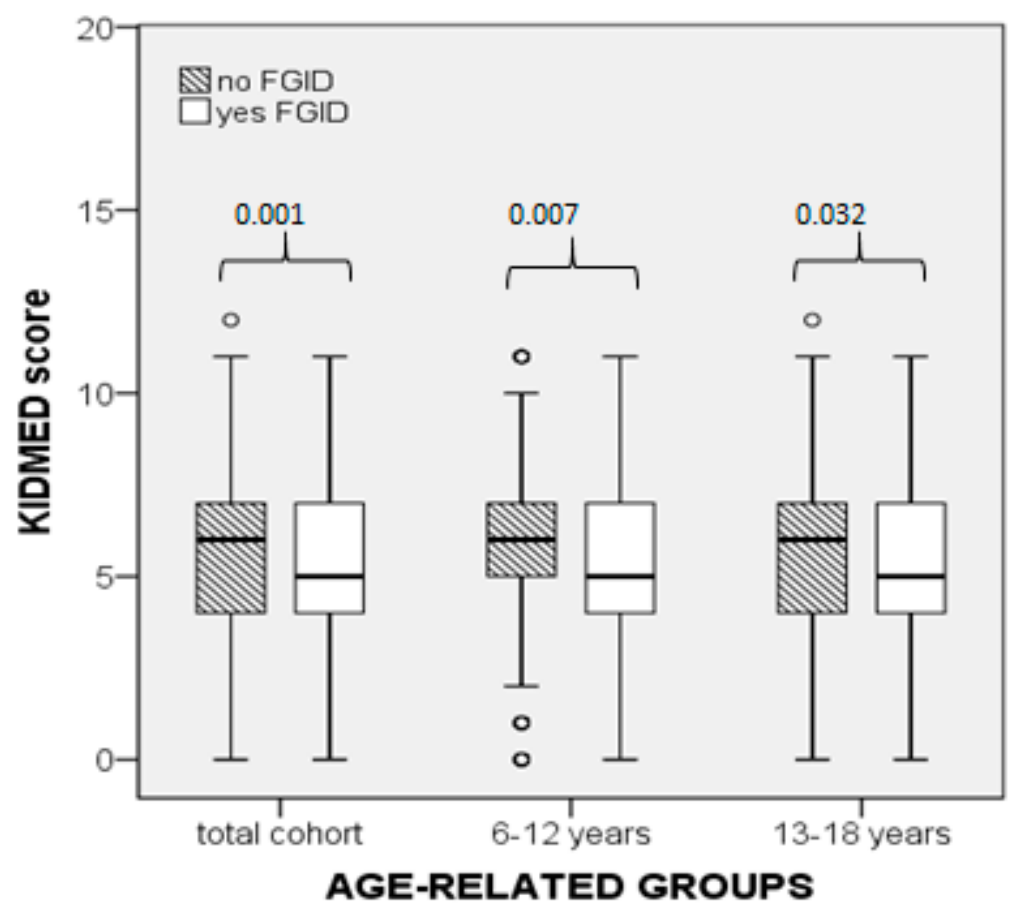

Figure 1. Comparison of the KIDMED scores between participants without functional gastrointestinal disorders (FGIDs) and those with FGIDs, in the cohort and the two age-subgroups (Mann-Whitney U test).

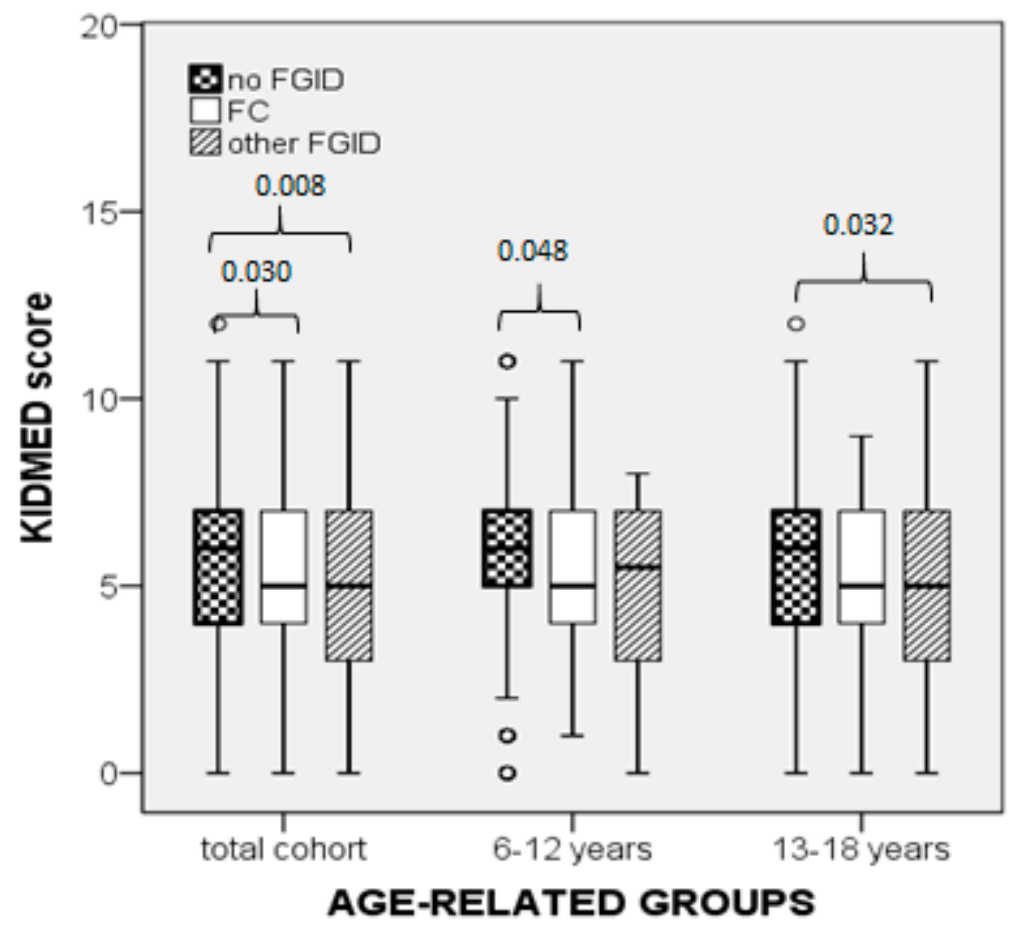

Figure 2. Comparisons of KIDMED score between participants without functional gastrointestinal disorders (FGIDs) and those with either functional constipation (FC) or other FGIDs, in the cohort and the two age-subgroups (Mann-Whitney $U$ test).

\subsection{Mediterranean Diet Adherence Categories and Relation with the Prevalence of Functional} Gastrointestinal Disorders

Further analysis based on the MD adherence-related categories showed that the highest proportion of the study population $(60.48 \%$ ) had average adherence to the MD, while $22.2 \%$ and $17.2 \%$ had good 
and poor adherence, respectively. A higher proportion of HSS had poor adherence to the MD compared to the ESC subgroup ( $p=0.035$, Table 2). The prevalence of FGIDs was lower among participants belonging to the good MD adherence category compared to those in the poor MD adherence one, differing significantly among the three MD adherence-related categories in the total FGID group $(p=$ $0.025)$ and the ESC subgroup ( $p=0.025)$, but not in the HSS subgroup ( $p=0.335$, Table 3$)$.

Table 2. Mediterranean diet adherence-related categories in the cohort and the two age-related subgroups.

\begin{tabular}{lcccc}
\hline \multirow{2}{*}{ MDA } & \multirow{2}{*}{ Cohort } & \multicolumn{3}{c}{ Age-Related Subgroups } \\
\cline { 3 - 5 } & & ESC & HSS & $\boldsymbol{p}$ (Fisher's Exact Test) * \\
\hline$n$ & 835 & 387 & 448 & \\
Good $(n,(\%))$ & $186(22.2)$ & $82(21.2)$ & $104(23.2)$ & 0.505 \\
Average $(n,(\%))$ & $505(60.4)$ & $250(64.6)$ & $255(56.9)$ & 0.028 \\
Poor $(n,(\%))$ & $144(17.2)$ & $55(14.2)$ & $89(19.9)$ & 0.035 \\
\hline
\end{tabular}

${ }^{*}$ ESC vs. HSS. MDA, Mediterranean diet adherence; ESC, elementary school children; HSS, high school students.

Table 3. Prevalence of FGIDs in the three MDA-related categories in participants with FGIDs and the respective two age-related subgroups.

\begin{tabular}{lccccc}
\hline \multirow{2}{*}{$\begin{array}{c}\text { Age Groups \& } \\
\text { Subgroups }\end{array}$} & \multirow{2}{*}{$\begin{array}{c}\text { Subjects with FGID } \\
(\boldsymbol{n})\end{array}$} & \multicolumn{4}{c}{ FGID Prevalence in the MDA-Related Categories } \\
\cline { 3 - 6 } & 184 & $29(15.8)$ & $115(62.8)$ & $40(21.7)$ & 0.025 \\
\hline Total & 67 & $6(9.0)$ & $49(73.1)$ & $12(17.9)$ & 0.025 \\
ESC & 117 & $23(19.7)$ & $66(56.4)$ & $28(23.9)$ & 0.335 \\
HSS & Average $(\boldsymbol{n}(\boldsymbol{\%}))$ & Poor $(\boldsymbol{n}$ (\%)) & $\boldsymbol{p}$ (Fisher's Exact Test) \\
\hline
\end{tabular}

FGIDs, functional gastrointestinal disorders; MDA, Mediterranean diet adherence; ESC, elementary school children; HSS, high school students.

\subsection{Multivariable Analysis Results}

Multivariable analysis (generalized linear model, binary logistic) with the prevalence of FGIDs as the dependent variable showed that the KIDMED score was significantly, inversely associated with the prevalence of FGIDs, while the age was positively associated. Regarding the relationship between the KIDMED score and the probability of developing FGIDs, our data showed that for each extra unit increase of the KIDMED score, the odds of developing FGIDs decreases by $8.9 \%$, after controlling for the age subgroup. Moreover, the regression model showed that the HSS age subgroup was at 1.6 times higher risk of developing FGIDs than the low-age subgroup, after controlling for the KIDMED score. A second binary logistic regression model was constructed with the prevalence of FC as the dependent variable, which revealed the KIDMED score as a significant independent predictor inversely associated with the FC, while the age was not a significant predictor. Controlling for the age subgroups, for each extra unit increase of the KIDMED score, the odds of developing FC decreases by about 9.1\% (Table 4).

Table 4. Results of the two multiple regression models (generalized linear models, binary logistic method) with dependent variables the occurrence of FGIDs and FC, respectively.

\begin{tabular}{lcccccc}
\hline \multirow{2}{*}{ Independent Variables } & \multicolumn{3}{c}{ FGID } & \multicolumn{3}{c}{ FC } \\
\cline { 2 - 7 } & $\mathbf{B}$ & $\boldsymbol{p}$ & $\boldsymbol{E x p}(\mathbf{B})$ & $\mathbf{B}$ & $\boldsymbol{p}$ & $\boldsymbol{E x p ( B )}$ \\
\hline KIDMED score & -0.113 & 0.001 & 0.893 & -0.097 & 0.021 & 0.907 \\
Age subgroups & 0.499 & 0.004 & 1.646 & 0.234 & 0.247 & 1.264 \\
\hline
\end{tabular}

\section{Discussion}

Results of the current study showed that children and adolescents free of FGIDs had a higher KIDMED score in comparison to those with FGIDs. Independent factors associated with the prevalence of FGIDs were the compliance with the MD (inverse association) and the age (positive association). 
The most common FGID in our study population was the FC that was negatively associated with the KIDMED score but not with the age-related subgroups.

The QPGS-RIII questionnaire, which was used to detect participants with FGIDs, is a qualified tool for epidemiological studies in children [23-25]. We found that $22.03 \%$ of the participants had an FGID, which was more frequent among adolescents compared to children. In agreement with our results, a previous multicenter study using the same questionnaire has shown that a percentage of $19 \%$ out of 13700 children from Mediterranean countries suffered FGIDs with an increased frequency in the adolescent group as well (20.7\% and $26.6 \%$ in children and adolescents, respectively) [2].

Compliance with the MD was assessed by using the KIDMED score, a tool that has been repeatedly validated [26,27]. We found that $22.2 \%$ of the study population showed good compliance with the MD, while most of them had an average KIDMED score (4-7). A previous study from Greece reported that only $11 \%$ of children and $8 \%$ of adolescents demonstrated good adherence to the MD, while the vast majority of them (73\% and $69 \%$ of children and adolescents, respectively) showed an average MD adherence [28]. In the present study, the proportion of children (21\%) and adolescents (22\%) having good adherence to the MD was rather low, although was higher than previously reported. These results can be attributed to the different regions studied and the impact of nutritional education during the years elapsed between the two studies. Data from other Mediterranean countries showed that the proportion of adolescents with good MD compliance varies widely [29,30]. A systematic review including 18 cross-sectional studies in Mediterranean countries reported that adherence to the MD differs among different countries but the pooled estimated percentage of poor adherence was $21 \%$ (confidence interval of $95 \%=0.14-0.27$ ) similar to ours (17.2 in the total sample, 19.9 in adolescents). The most relevant difference was in relation to age: $27 \%$ poor adherence to MD in subjects under 12 years compared to $19 \%$ in those over 12 years, while our results showed worst compliance in those over 12 years ( $17.9 \%$ vs $23.9 \%$ ) [2,31].

Previous studies in children and adolescents have demonstrated a correlation between compliance with the MD and diverse pathological conditions, such as obesity, asthma, and recurrent cold [32-34]. Regarding the potential association of MD adherence with FGIDs, data in adults support a beneficial effect of the MD on the onset of gastrointestinal (GI) symptoms in patients with GI disease, both organic (inflammatory bowel disease) and functional (IBS, functional dyspepsia, gastroesophageal reflux) [35]. A case-control study in adult patients with ulcerative colitis, Crohn's disease, IBS, or gastroesophageal reflux, showed that consumption of functional foods, including probiotics, prebiotics, antioxidants, fiber, vitamins, minerals, etc., and adherence to the MD was lower in patients than in controls [36]. A study from Southern Italy by Zito et al. [37] investigated the association between adherence to the $\mathrm{MD}$ and onset of symptoms in adults with functional dyspepsia or IBS. They demonstrated an inverse correlation between compliance with the MD and appearance of gastrointestinal symptoms, suggesting that good adherence to the MD can prevent gastrointestinal symptoms in adults. Moreover, the latter study showed that only the groups of younger patients (17-24 years and 25-34) with functional dyspepsia and IBS had a significantly poorer MD adherence compared to the respective age-matched control groups. A case-control study compared the MD adherence of children and adolescents suffering from inflammatory bowel disease with that in an age-matched population with FGIIs (gastroesophageal reflux and functional constipation). It was found that children/adolescents with inflammatory bowel syndrome had poorer adherence to the MD than those with FGIDs. However, there is no data on the association of MD adherence with the prevalence of FGIDs in children and adolescents [38]. Our results extend the previously reported findings in adults, indicating that good adherence to the MD may exert a preventive action on the onset of FGID in children and adolescents as well.

In our study, the participants without FGIDs had a significantly higher KIDMED score compared to those with FGIDs. Further analysis within each age-related subgroup confirmed that the KIDMED score in both age-related subgroups was higher in the absence of FGIDs compared to the respective age subgroups with FGIDs. Classification of the study population into three categories of MD adherence showed that the proportion of subjects without FGIDs differed significantly among the three categories, 
being higher in that with good MD adherence. Further analysis using multivariable regression confirmed the inverse association of adherence to the MD with the prevalence of FGIDs, after adjusting for the age subgroups. Based on our data, it is estimated that an increase of the KIDMED score by one unit decreases the probability of developing FGIDs by about $9 \%$. Moreover, the model revealed the age as a significant independent (positive) predictor of FGIDs, with the adolescents being at 1.6 times higher risk of developing FGIDs.

The most common FGID in the current study population was the FC, accounting for about $66 \%$ of the FGIDs. The KIDMED score in participants with FC was significantly lower compared to that in the non-FGID group, both in the total study population and in the subgroup of ESC, but not in HSS one. Multifactorial analysis confirmed that good adherence to the MD was associated with a lower prevalence of FC, while the age was not a significant predictor.

FGID symptoms may be triggered by several factors, including genetic, epigenetic, and environmental ones. Diet is the most important environmental factor associated with GI disturbances. Quantitative analysis of diet patterns using scores or indices instead of studying individual nutrients has significantly contributed to epidemiological studies. Dietary patterns represent a broader picture of food and nutrient consumption, potentially interacting with each other, which may be more predictive of disease risk than individual foods or nutritional components. This approach cannot be specific about the particular nutrients responsible for the observed differences in disease risk, and thereby information about biological relationships between dietary components and disease risk would be a challenge [39]. The protective effect of the MD on FGIDs may be due to its individual nutritional components, but it is more likely that the MD as a dietary pattern affects the structure and the function of the gut [40-42].

Moreover, the effect of the MD on gut microbiota may be an additional factor contributing to low FGIDs. Previous studies demonstrated that good adherence to the MD was associated with lower Escherichia coli counts and a higher Bifidobacteria to E. coli ratio, while ingestion of food rich in fiber was associated with higher microbial diversity with the predominance of Prevotella over Bacteroides [11,40,43-45]. A recent review summarized existing data from clinical trials and observational studies investigating the effect of the MD adherence on the metabolome and microbiome profiles, and the potential association with cardiovascular and gastrointestinal diseases. The authors concluded that current evidence is inadequate for a definitive conclusion to be drawn as to whether the gut microbiome contributes to the MD-associated beneficial health outcomes [46]. Additional properties of the MD potentially associated with a beneficial effect on FGIDs include the antioxidant and anti-inflammatory effects of the MD components.

We found that the KIDMED score was lower in the FGID group compared to non-FGID group in the total cohort and ESC, but not in the HSS (Figure 1). Similarly, the prevalence of FGID differed significantly among the three MD adherence categories in the cohort and ESC but not in the HSS groups. There is no previously published data on MD adherence of children and adolescents in association with FGIDs to compare or interpret. Consequently, we can only speculate that in children the diet is a predominant factor influencing the onset of FGID symptoms, while in adolescents multiple additional factors, mainly personality-associated, may have a higher impact on the prevalence of FGID. A recent study in a cohort of adolescents (age 13-18 years) demonstrated that personality and quality of life are significant factors associated with the prevalence of FGIDs (defined by the Rome III criteria). It was found that adolescents with FGIDs had higher scores in personality traits, including hostility and aggression, low self-esteem, emotional instability, as well as lower scores in the quality of life domains, i.e., physical, social, emotional, and school functioning, compared to those without FGIDs [47]. In addition, previous studies reported that the incidence of psychosocial impairments, such as major depression disorders and social anxiety disorders, was higher in adolescents than in children [48,49]. These data combined suggest that psychosocial factors may have obscured the role of the MD in the development of FGID in the HSS group of our study. The strengths of our study lie in the fact that this is the first report on the association between MD adherence and FGIDs in children and adolescents 
with a sufficient number of participants for detecting statistically significant differences. The study sample, although not quite representative of the entire Greek population, still represents a typical sample of urban, upper-middle income Greek families. Moreover, the data collection procedure was not influenced by seasonal variations that could possibly affect food intake choices by participants, since all data were collected during spring. The main limitation is the cross-sectional design, which allows assessment of valid associations but not conclusions on causality.

\section{Conclusions}

Results of the current study indicate that good adherence to the MD decreases the risk of developing FGIDs in children and adolescents. The mechanisms underlying this association and the causality between the MD and FGIDs need further clarification. If the current study findings are confirmed with the use of extensive dietary assessments, metabolomic analysis and microbiome assessments able to provide a much more complete picture of the diet-health relationship [46], then intervention studies should be designed in order to promote compliance to healthy dietary patterns starting in early childhood. Until then, encouraging children and adolescents to follow the MD could have a place among other measures in preventing FGIDs or minimizing the symptoms.

Author Contributions: Conceptualization and supervision, T.K.-L.; Data acquisition, E.K.\& K.A.; Formal analysis, D.P. \& C.A.; Interpretation, C.A. \& T.-K.L.; Writing-Original Draft Preparation, C.A.; Writing-Review \& Editing C.A. \& T.K.-L.

Funding: This research received no external funding.

Conflicts of Interest: The authors declare no conflict of interest.

\section{References}

1. Drossman, D. The functional gastrointestinal disorders and the Rome III Process. Gastroenterology 2006, 130, 1377-1390. [CrossRef] [PubMed]

2. Scarpato, E.; Kolacek, S.; Jojkic-Pavkov, D.; Konjik, V.; Živković, N.; Roman, E.; Kostovski, A.; Zdraveska, N.; Altamimi, E.; Papadopoulou, A.; et al. Prevalence of Functional Gastrointestinal Disorders in Children and Adolescents in the Mediterranean Region of Europe. Clin. Gastroenterol. Hepatol. 2018, 16, 870-876. [CrossRef] [PubMed]

3. Hoekman, R.; Rutten, J.M.T.M.; Lieger, A.M.; Benninga, M.A.; Dijkgraaf, M.G.W. Annual costs of care for pediatric Irritable Bowel Syndrome; Functional Abdominal Pain and Functional Abdominal Pain Syndrome. J. Pediatrics 2015, 167, 1103-1108. [CrossRef] [PubMed]

4. Drossman, D.A.; Hasler, W.L. Rome IV-Functional GI Disorders: Disorders of Gut-Brain Interaction. Gastroenterology 2016, 150, 1257-1261. [CrossRef] [PubMed]

5. Bonilla, S.; Saps, M. Early life events predispose the onset of childhood functional gastrointestinal disorders. Rev. De Gastro Mex 2013, 78, 82-91. [CrossRef] [PubMed]

6. Hyams, J.S.; Di Lorenzo, C.; Saps, M.; Shulman, R.J.; Staiano, A.M.; van Tilburg, M. Childhood Functional Gastrointestinal Disorders: Child/Adolescent. Gastroenterology 2016, 150, 1456-1468. [CrossRef] [PubMed]

7. Rasquin, A.; Di Lorenzo, C.; Forbes, D.; Guiralde, E.; Hyams, S.J.; Staiano, A.; Walker, L.S. Childhood Functional Gastrointestinal Disorders: Child/Adolescent. Gastroenterology 2006, 130, 1527-1537. [CrossRef] [PubMed]

8. Wilson, K.; Hill, R.J. The role of food intolerance in functional gastrointestinal disorders in children. Aust. Fam. Physician 2014, 43, 686-689.

9. Chumpitazi, B.P.; Weilder, E.M.; Lu, D.Y.; Tsai, C.M.; Shulman, R.J. Self perceived food intolerances are common and associated with clinical severity in childhood irritable bowel syndrome. J. Acad. Nutr. Diet. 2016, 116, 1458-1464. [CrossRef]

10. Gibson, P.R.; Varney, J.; Malakar, S.; Muir, J.G. Food and functional bowel disease: Food components and irritable bowel syndrome. Gastroenterology 2015, 148, 1158-1174. [CrossRef] 
11. Metzler-Zebeli, B.U.; Canibe, N.; Montagne, L.; Freire, J.; Bosi, P.; Prates, J.A.M.; Tanghe, S.; Trevisi, P. Resistant starch reduces large intestinal $\mathrm{pH}$ and promotes fecal lactobacilli and bifidobacteria in pigs. Animal 2019, 13, 64-73. [CrossRef] [PubMed]

12. Dahl, W.J.; Stewart, M.L. Position Statement of the Academy of Nutrition and Dietetics: Health implications of dietary fiber. J. Acad. Nutr. Diet. 2015, 115, 1861-1870. [CrossRef] [PubMed]

13. Stewart, M.L.; Schroeder, N.M. Dietary treatments for childhood constipation: Efficacy of dietary fiber and whole grains. Nutr. Rev. 2013, 71, 98-109. [CrossRef] [PubMed]

14. Weber, T.K.; Toporovski, M.S.; Tahan, S.; Neufeld, C.B.; de Morais, M.B. Dietary fiber mixture in pediatric patients with controlled chronic constipation. JPGN 2014, 58, 297-302. [CrossRef] [PubMed]

15. Kokke, F.T.M.; Scholtens, P.A.M.J.; Alles, M.S.; Decates, T.S.; Fiselier, T.J.; Tolboom, J.J.; Kimpen, J.L.; Benninga, M.A. A dietary fiber mixture versus Lactulose in the treatment of childhood constipation: A double-blin randomized controlled trial. JPGN 2008, 47, 592-597. [CrossRef] [PubMed]

16. Sung, V.; Hiscock, H.; Tang, M.L.K.; Mensah, F.K.; Nation, M.L.; Satzke, C.; Heine, R.G.; Stock, A.; Barr, R.G.; Wake, M. Treating Infant colic with the probiotic Lactobacillus reuteri: Double blind; placebo controlled randomised trial. BMJ 2014, 348, 2107-2118. [CrossRef] [PubMed]

17. Newlove-Delgado, T.V.; Martin, A.E.; Abbott, R.A.; Bethel, A.; Thompson-Coon, J.; Whear, R.; Logan, S. Dietary interventions for recurrent abdominal pain in childhood. Cochrane Database Syst. Rev. 2017, 3, CD010972. [CrossRef] [PubMed]

18. Chumpitazi, B.P.; Hollister, E.B.; Oezguen, N.; Tsai, C.M.; McMeans, A.R.; Luna, R.A.; Savidge, T.C.; Versalovic, J.; Shulman, R.J. Gut microbiota influences low fermentable substrate diet efficacy in children with irritable bowel syndrome. Gut Microbes 2014, 5, 165-175. [CrossRef] [PubMed]

19. Trichopoulou, A.; Lagiou, P. Healthy traditional Mediterranean diet: An expression of culture, history and lifestyle. Nutr. Rev. 1997, 55, 383-389. [CrossRef]

20. Iaccarino Idelson, P.; Scalfi, L.; Valerio, G. Adherence to the Mediterranean Diet in children and adolesents: A systematic review. Nutr. Metab. Cardiovasc Dis. 2017, 27, 283-299. [CrossRef] [PubMed]

21. Bouzios, I.; Chouliaras, G.; Chrousos, G.P.; Roma, E.; Gemou-Engesaeth, V. Functional gastrointestinal disorders in Greek Children based on ROME III criteria: Identifying the child at risk. Neurogastroenterol. Motil. 2017, 29, e12951. [CrossRef] [PubMed]

22. Serra-Majem, L.; Ribas, L.; Ngo, J.; Ortega, R.M.; Garcia, A.; Perez-Rodrigo, C.; Aranceta, J. Food, Youth and the Mediterranean Diet in Spain. Development of KIDMED; Mediterranean Diet Quality Index in children and adolescents. Public Health Nutr. 2004, 7, 931-935. [CrossRef] [PubMed]

23. Caplan, A.; Walker, L.S.; Rasquin, A. Development and preliminary validation of the Questionnaire on Pediatric Gastrointestinal Symptoms to assess functional gastrointestinal disorders in children and adolescents. JPGN 2005, 41, 296-304. [CrossRef] [PubMed]

24. Caplan, A.; Walker, L.S.; Rasquin, A. Validation of the Pediatric Rome II Criteria for functional gastrointestinal symptoms using the Questionnaire on Pediatric Gastrointestinal Symptoms. JPGN 2005, 41, 305-316. [CrossRef] [PubMed]

25. Walker, L.S.; Lipani, T.A.; Greene, J.W.; Caines, K.; Stutts, J.; Polk, D.B.; Caplan, A.; Rasquin-Weber, A. Recurrent abdominal pain: Subtypes based on the Rome II criteria for pediatric functional gastrointestinal disorders. JPGN 2004, 38, 187-191. [CrossRef]

26. Mariscal-Arcas, M.; Rivas, A.; Velasco, J.; Ortega, M.; Caballero, A.M.; Olea-Serrano, F. Evaluation of the Mediterranean Diet Quality Index (KIDMED) in children and adolescents in Southern Spain. Public Health Nutr. 2008, 12, 1408-1412. [CrossRef]

27. Štefan, L.; Prosoli, R.; Juranko, D.; Čule, M.; Milinović, I.; Novak, D.; Sporiš, G. The reliability of the Mediterranean Diet Quality Index (KIDMED) Questionnaire. Nutrients 2017, 9, 419. [CrossRef]

28. Kontogianni, M.D.; Vidra, N.; Farmaki, A.E.; Koinaki, S.; Belogianni, K.; Sofrona, S.; Magkanari, F.; Yannakoulia, M. Adherence rates to the Mediteranean Diet are low in a representative sample of Greek children and adolescents. J. Nutr. 2008, 138, 1951-1956. [CrossRef]

29. Noale, M.; Nardi, M.; Limongi, F.; Siviero, P.; Caregaro, L.; Crepaldi, G.; Maggi, S.; Mediterranean Diet Foundation Study Group. Adolescents in southern regions of Italy adhere to the Mediterranean diet more than those in the northern regions. Nutr. Res. 2014, 34, 771-779. [CrossRef] 
30. Novak, D.; Stefan, L.; Prosoli, R.; Emeljanovas, A.; Miezene, B.; Milanovic, I.; Radisavljević-Janić, S. Mediterranean Diet and its correlates among adolescents in non-Mediterranean European countries: A population based study. Nutrients 2017, 9, 177. [CrossRef]

31. García Cabrera, S.; Herrera Fernández, N.; Rodríguez Hernández, C.; Nissensohn, M.; Román-Viñas, B.; Serra-Majem, L. KIDMED test: Prevalence of low adherence to the Mediterranean Diet in children and young; A systematic review. Nutr. Hosp. 2015, 32, 2390-2399. [CrossRef] [PubMed]

32. Calatayud-Saez, F.M.; Calatayud Moscoso Del Prado, B.; Gallego Fernandez-Pacheco, J.G.; Gonzalez-Martin, C.; Alguacil Merino, L.F. Mediterranean diet and childhood asthma. Allergol. Immunopathol. (Madr) 2016, 44, 99-105. [CrossRef] [PubMed]

33. Esteban-Cornejo, I.; Izquierdo-Gomez, R.; Gomez-Martinez, S.; Padilla-Moledo, C.; Castro-Pinero, J.; Marcos, A.; Veiga, O.L. Adherence to the Mediterranean diet and academic performance in youth: The UP\&DOWN study. Eur. J. Nutr. 2016, 55, 1133-1140. [CrossRef] [PubMed]

34. Calatayud, F.M.; Calatayud, B.; Gallego, J.G.; Gonzalez-Martin, C.; Alguacil, L.F. Effects of Mediterranean diet in patients with recurring colds and frequent complications. Allergol. Immunopathol. (Madr) 2017, 45, 417-424. [CrossRef]

35. Reddavide, R.; Rotolo, O.; Caruso, M.; Stasi, E.; Notarnicola, M.; Miraglia, C.; Antonio, N.; Tiziana, M.; Gian, L.D.A.; Francesco, D.M.; et al. The role of diet in the prevention and treatment of Inflammatory Bowel Diseases. Acta Biomed. 2018, 89 (Suppl. 9), 60-75. [CrossRef]

36. Elmaliklis, I.N.; Liveri, A.; Ntelis, B.; Paraskeva, K.; Goulis, I.; Koutelidakis, A.E. Increased Functional Foods' Consumption and Mediterranean Diet adherence may have a protective effect in the appearance of gastrointestinal diseases: A case-control study. Medicines 2019, 6, 50. [CrossRef] [PubMed]

37. Zito, F.P.; Polese, B.; Vozzella, L.; Gala, A.; Genovese, D.; Verlezza, V.; Medugno, F.; Santini, A.; Barrea, L.; Cargiolli, M.; et al. Good adherence to Mediterranean diet can prevent gastrointestinal symptoms: A survey from Southern Italy. World J. Gastrointest Pharm. 2016, 7, 564-571. [CrossRef] [PubMed]

38. Strisciuglio, C.; Giugliano, F.; Martinelli, M.; Cenni, S.; Greco, L.; Staiano, A.; Miele, E. Impact of environmental and familial factors in a cohort of pediatric patients with inflammatory bowel disease. JPGN 2017, 64, 569-574. [CrossRef] [PubMed]

39. Hu, F.B. Dietary pattern analysis: A new direction in nutritional epidemiology. Curr. Opin. Lipidol. 2002, 13, 3-9. [CrossRef]

40. De Filippis, F.; Pellegrini, N.; Vannini, L.; Jeffery, I.B.; La Storia, A.; Laghi, L.; Serrazanetti, D.I.; Di Cagno, R.; Ferrocino, I.; Lazzi, C.; et al. High-level adherence to a Mediterranean diet beneficially impacts the gut microbiota and associated metabolome. Gut 2015, 65, 1-10. [CrossRef]

41. Del Chierico, F.; Vernocchi, P.; Dallapiccola, B.; Putignani, L. Mediterranean diet and health: Food effects on gut microbiota and disease control. Int. J. Mol. Sci. 2014, 15, 11678-11699. [CrossRef] [PubMed]

42. David, L.A.; Maurice, C.F.; Carmody, R.N.; Gootenberg, D.B.; Button, J.E.; Wolfe, B.E.; Ling, A.V.; Devlin, A.S.; Varma, Y.; Fischbach, M.A.; et al. Diet rapidly and reproducibly alters the human gut microbiome. Nature 2014, 505, 559-563. [CrossRef] [PubMed]

43. Mitsou, E.K.; Kakali, A.; Antonopoulou, S.; Mountzouris, K.C.; Yannakoulia, M.B.; Panagiotakos, D.B.; Kyriacou, A. Adherence to the Mediterranean diet is associated with the gut microbiota pattern and gastrointestinal characteristics in an adult population. Br. J. Nutr. 2017, 117, 1645-1655. [CrossRef] [PubMed]

44. Simpson, H.L.; Campbell, B.J. Review article: Dietary fibre-microbiota interactions. Aliment. Pharm. 2015, 42, 158-179. [CrossRef] [PubMed]

45. Shortt, C.; Hasselwander, O.; Meynier, A.; Nauta, A.; Fernández, E.N.; Putz, P.; Rowland, I.; Swann, J.; Türk, J.; Vermeiren, J.; et al. Systematic review of the effects of the intestinal microbiota on selected nutrients and non-nutrients. Eur. J. Nutr. 2018, 57, 25-49. [CrossRef] [PubMed]

46. Jin, Q.; Black, A.; Kales, S.N.; Vattem, D.; Ruiz-Canela, M.; Sotos-Prieto, M. Metabolomics and microbiomes as potential tools to evaluate the effects of the Mediterranean diet. Nutrients 2019, 11, 207. [CrossRef] [PubMed]

47. Ranasinghe, N.; Devanarayana, N.M.; Rajindrajith, S.; Perera, M.S.; Nishanthinie, S.; Warnakulasuriya, T.; de Zoysa, P.T. Functional gastrointestinal diseases and psychological maladjustment, personality traits and quality of life. BMC Gastroenterol. 2018, 18, 33. [CrossRef] [PubMed] 
48. Duncan, L.; Georgiades, K.; Wang, L.; Comeau, J.; Ferro, M.A.; Van Lieshout, R.; Szatmari, P.; Bennett, K.; MacMillan, H.L.; Lipman, E.L.; et al. The 2014 Ontario Child Health Study Emotional Behavioural Scales (OCHS-EBS) Part I: A Checklist for dimensional measurement of selected DSM-5 disorders. Can. J. Psychiatry 2018. [CrossRef] [PubMed]

49. Georgiades, K.; Duncan, L.; Wang, L.; Comeau, J.; Boyle, M.H.; 2014 Ontario Child Health Study Team. Six-Month Prevalence of Mental Disorders and Service Contacts among Children and Youth in Ontario: Evidence from the 2014 Ontario Child Health Study. Can. J. Psychiatry 2019, 64, 246-255. [CrossRef]

(C) 2019 by the authors. Licensee MDPI, Basel, Switzerland. This article is an open access article distributed under the terms and conditions of the Creative Commons Attribution (CC BY) license (http://creativecommons.org/licenses/by/4.0/). 